\title{
EPISTEMOLOGIA DA COMPLEXIDADE E METODOLOGIA DE PROJETOS NA EDUCAÇÃO BÁSICA: Caminhos Possíveis Para a Inter e a Transdisciplinaridade
}

\author{
Marcio Antonio Raiol Santos ${ }^{1}$ \\ Lívia Maria Neves Bentes ${ }^{2}$ \\ Nádia dos Passos Serique ${ }^{3}$
}

\begin{abstract}
RESUMO
Este artigo apresenta quatro temas que se interpenetram: a Teoria da Complexidade, a Interdisciplinaridade, a Transdisciplinaridade e a Metodologia de Projetos. Nele procuramos articular a fundamentação teórico-metodológica da Interdisciplinaridade e da Transdisciplinaridade, a partir de uma perspectiva de aproximação e complementaridade, alicerçada na Epistemologia da Complexidade. Tomando como premissa a necessidade de produção de um conhecimento pertinente no âmbito da Educação Básica, com vistas à valorização da realidade dos educandos, bem como de seu protagonismo nos processos educativos, lançamos como proposta metodológica a utilização da Metodologia de Projetos. A partir deste contexto, nosso principal objetivo é contribuir com as discussões sobre a Interdisciplinaridade e a Transdisciplinaridade na Educação Básica, destacando o papel dos docentes como possíveis catalisadores do processo de planejamento/execução de ações que direcionem o cotidiano da escola para a realidade complexa em que a sociedade contemporânea se insere.

Palavras-chave: Interdisciplinaridade. Transdisciplinaridade. Complexidade. Metodologia de projetos.
\end{abstract}

\section{EPISTEMOLOGY OF COMPLEXITY AND PROJECT METHODOLOGY IN BASIC EDUCATION:} POSSIBLE PATHWAYS FOR INTER AND TRANSDISCIPLINARITY

\begin{abstract}
This article presents four themes that interpenetrate: The Theory of Complexity, the Interdisciplinarity, the Transdisciplinarity and the Methodology of Projects. In it we seek a theoretical-methodological foundation of Interdisciplinarity and Transdisciplinarity, from a perspective of approximation and complementarity, based on the epistemology of Complexity. Taking as a premise the need of production of a pertinent knowledge in the scope of basic education, with a view to valuing the students' reality, as well as its protagonism in the educational processes, we launched with methodological proposal the use of the project methodology. From this context, our main objective is to contribute with the discussions about the interdisciplinarity and transdisciplinarity on basic education, highlighting in this context, the docents' role as possible catalyzers of the process of planning/carrying out activities that guide the daily life of the school to the complex reality in which the contemporary society is inserted.

Keywords: Interdisciplinarity. Transdisciplinarity. Complexity. Project methodology.
\end{abstract}

RECEBIDO EM: 27/3/2018

ACEITO EM: 8/6/2018

\footnotetext{
${ }_{1}^{1}$ Professor titular da Universidade Federal do Pará. Docente do Núcleo de Estudos Transdisciplinares da Educação Básica (NEB Ufpa) e do Programa de Pós-Graduação em Currículo e Gestão da Escola Básica (Ufpa). Licenciado pleno em Educação Física pela Universidade do Estado do Pará (1994), especialista em Metodologia do Ensino da Educação Física Escolar pela Universidade Federal do Pará (1996), mestre (2001) e doutor (2005) em Educação pela Universidade Metodista de Piracicaba. Atualmente exerce o cargo de coordenador de Educação Básica e Técnica Profissional Proeg - Ufpa. Desenvolve suas investigações nas áreas da Educação e do Ensino, com ênfase em Ludicidade e Educação; Currículo e Educação Básica; Teoria da Complexidade e Educação; Interdisciplinaridade e Transdisciplinaridade; Formação e Práticas Docentes em Educação Física. Líder do Grupo de Pesquisa Práticas Pedagógica para o Ensino na Educação Básica, registrado no Diretório dos Grupos de Pesquisa do CNPq. marsraiol@gmail.com

${ }^{2}$ Graduada no Curso de Licenciatura Plena em Educação Física pela Universidade Federal do Pará (Ufpa/Castanhal, 2015). Professora da Escola de Aplicação da Ufpa. É membro do Grupo de Pesquisa em Práticas Pedagógicas para o Ensino na Educação Básica (GPRAPE). Possui Graduação no curso de Bacharelado em Comunicação Social, com habilitação em Jornalismo, atuando na área de Educomunicação. livia.bentes@hotmail.com

${ }^{3}$ Professora da Rede Municipal de Ensino de Macapá. Licenciada e bacharel em Ciências Sociais pela Universidade Federal do Amapá (2005). Especialista em Coach Educacional pela Universidade Cândido Mendes-RJ (com intercâmbio na Finlândia, 2017). Mestranda em Currículo e Gestão da Escola Básica na Universidade Federal do Pará (2017). Membro do Grupo de Pesquisa em Prática Pedagógica para o Ensino da Educação Básica-Ufpa.nserik@hotmail.com
} 


\title{
EPISTEMOLOGIA DA COMPLEXIDADE E EDUCAÇÃO BÁSICA: Os Cinco Desafios Contemporâneos da Educação
}

\begin{abstract}
Há inadequação cada vez mais ampla, profunda e grave entre os saberes separados, fragmentados, compartimentados entre disciplinas, e, por outro lado, realidades ou problemas cada vez mais polidisciplinares, transversais, multidimensionais, transnacionais, globais, planetários. Em tal situação tornam-se invisíveis: os conjuntos complexos; as interações e retroações entre parte e todo; as entidades multidimensionais; os problemas essenciais (MORIN, 2001a, p. 13).
\end{abstract}

Nas últimas décadas, Edgar Morin vem dedicando cada vez mais esforços em direcionar suas reflexões para o campo educativo. $O$ autor e seus colaboradores buscam nesses textos, voltados especificamente para questões educativas, ressaltar direcionamentos, caminhos ou eixos "transversáteis". ${ }^{4}$ As reflexões colocadas nos textos pedagógicos vêm sendo trabalhadas intensamente pelo autor e assumem importância crucial ao solicitar dos agentes educativos (educandos, educadores, gestores e comunidade em geral) uma ação mais reflexiva de si e do mundo, sem esquecer o contexto contemporâneo que se caracteriza pelos seus desafios e desdobramentos.

De modo geral, percebe-se uma preocupação em alertar para as possibilidades nefastas do conhecimento científico, ao tomá-lo como verdade absoluta e imutável (dogma); para o aumento das agressões à natureza; para a necessidade de nos considerarmos cada vez mais moradores de nossa pátria planetária - ou "Terra Pátria" - (MORIN, 2000b) e para as aproximações entre a Filosofia, as Ciências Biológicas, Humanas e Físico-Químicas, no afã de propiciar um entendimento mais complexo de qualquer fenômeno, entre eles os fenômenos humanos.

Tal "dogma científico" colabora enormemente para a consolidação das fragmentações dos saberes científicos em campos fechados e incomunicáveis. É como se cada área do conhecimento, cada vez mais, alargasse e delimitasse suas fronteiras, fechando-se em suas especificidades. Estas características também têm suas raízes fincadas na Educação Básica, na qual seus princípios são fortalecidos, por meio de uma configuração dos saberes escolares, tornando-se transposições da fragmentação da ciência moderna.

Tomando como base os escritos de Morin (2001a), iniciaremos esta resumida incursão sistematizando os principais desafios enfrentados pelos cidadãos do planeta e que afetam diretamente os esforços educativos. Tais desafios apresentam-se de forma perniciosa, porém não são impossíveis de solução.

O primeiro desafio educacional que desejamos destacar é o da dissociação e fragmentação entre os diferentes campos de conhecimento, que dificulta a muitos educadores, pesquisadores e pensadores perceberem e proporem soluções para uma grande gama de problemas, que são essencialmente multifacetados e complexos, consequentemente exigindo ações multifacetadas e complexas.

\footnotetext{
4 "Trans" que denota movimento "para além de" e "através de", ou seja, que possa percorrer vários campos de conhecimento; e "versátil" para adaptar-se em todos os campos. 
A hiperespecialização, que se caracteriza pela exacerbada especificidade das áreas, não permite um olhar mais profundo, uma visão mais global e complexa (visão de conjunto), não apenas do conhecimento científico, mas de sua interconexão e diálogo com as diferentes formas de conhecimento. Desse modo, um professor ao acreditar que sua disciplina por si só pode fornecer o máximo de conhecimento necessário, está impedido de visualizar as diferentes facetas das realidades multidimensionais que o cercam, bem como os problemas multirreferenciais e os fenômenos complexos.

No atual contexto da sociedade contemporânea, alicerçada por múltiplas informações, meios de acesso e um desenvolvimento grandioso de bens e serviços, os problemas estão se tornando cada vez mais planetários, ocorrendo urgência de se repensar alternativas que os amenizem. Capra (1996) alerta que quanto mais nos debruçamos nos estudos sobre os principais problemas de nossa época, mais somos levados a perceber que eles não podem ser entendidos isoladamente, pois são problemas sistêmicos, que estão interligados e são interdependentes.

Dessa maneira, é preciso situar o papel da escola nesse cenário de mudanças e incertezas, pois a instituição escolar abriga uma carga de responsabilidade significativa em relação às respostas para as demandas das mais diversas questões sociais. Para isso, há de se considerar uma educação que vá além das disciplinas, mas sem abandoná-las e, sim, envolvê-las num diálogo que permita a articulação nos/dos mais diferentes contextos, tecendo e religando os saberes. Morin acredita que "a inteligência que só sabe separar, fragmentar o complexo (...) em pedaços separados, fracionar os problemas (...) atrofia as possibilidades de compreensão e de reflexão" (MORIN, 2001a, p. 14).

Inegavelmente, o desenvolvimento disciplinar das Ciências trouxe vantagens tecnológicas e melhorias aos níveis de vida da população mundial. Essa mesma especialização, no entanto, que causou avanços significativos, colocou em caixinhas, em nichos segregados, os diversos campos teóricos e não consegue responder às demandas da sociedade contemporânea, portanto mostra-se insuficiente.

$O$ ensino tradicional é um grande perpetuador da fragmentação. Todos os níveis da Educação Básica possuem um forte traço de disjunção, separação de problemas, levando os educadores a reduzirem o complexo ao simples, ou seja, o pensamento que permite ao especialista um ótimo desempenho em sua área de domínio, com uma visão determinista, mecanicista, formalista, ignorando o que é subjetivo, afetivo, lúdico, livre e criativo.

Conforme Morin (2001a), dever-se-ia estar atento na Educação Básica ao agravamento da disjunção dos saberes e à dificuldade posterior para correlacioná-los, e abrir espaços à formidável plasticidade do cérebro/mente humano para contextualizar e integrar, o que deve ser valorizado e não suprimido.

O segundo grande desafio educacional consiste na cisão entre a cultura humanista e a cultura científica (MORIN, 2001a, p. 17), iniciada no século 19 e agravada nos séculos 20 e 21, fato que trouxe consequências para ambas. De um lado a cultura científica, ao separar as áreas do conhecimento, não realizou reflexões sobre a função social de suas descobertas, ou seja, o pensamento ético não fazia parte dos afazeres de um cientista e isso acabava interferindo na sua maneira de pensar e agir. Espera-se que a escola, entretanto, entre outras tarefas, cumpra seu compromisso ético, que é fazer 
com que o indivíduo compreenda a sua realidade e saiba inferir e refletir de maneira consciente acerca dos problemas globais. De outro lado, temos a cultura humanista, que se caracteriza por ser genérica, por levantar grandes questionamentos humanos e estimular a reflexão sobre os saberes, todavia ignora os avanços tecnológicos e mantém, frequentemente, uma postura preconceituosa com relação às Ciências Exatas e Naturais.

Edgar Morin, em muitas de suas obras, vem alertando para o duplo preconceito que ocorre entre alguns dos membros dos grandes grupos, que compõem, grosso modo, o mundo científico. Por um lado, alguns constituintes da cultura humanista defendem que as Ciências (ditas exatas) são um amontoado de saberes abstratos e muitas vezes ameaçadores, enquanto alguns participantes do mundo técnico-científico acreditam que a cultura humanista é apenas uma espécie de ornamento ou luxo estético (pouco objetiva). Tais comportamentos (preconceitos perniciosos e infundados) só contribuem para manter o ser humano e o mundo, do qual fazem parte, separados por formas de pensamentos e atitudes.

O terceiro desafio da educação consiste no conhecimento como maior e mais importante capital. Nunca em toda a História da humanidade o conhecimento foi tão valorizado, convertendo-se a cada dia no principal capital capaz de colocar um grupo social em destaque ou alijá-lo dos processos econômicos, técnicos, sociais e políticos. A característica cognitiva ganhou importância de maneira única e, assim o "pensamento" é a cada dia o capital mais precioso para o indivíduo e a sociedade. Isso faz com que o saber seja ainda mais simplificador, fragmentado e específico de cada área do pensamento, ao mesmo tempo que adquire um caráter de valor, ditado pelos processos econômicos da sociedade.

Os atores educacionais não podem ignorar este fato e se manterem como uma cidadela isolada, cercada por muros de "tradições estéreis", impedindo-se de experimentar os novos saberes, sob pena de impossibilitar ou dificultar a todos um acesso mais efetivo a processos de produção e difusão dos conhecimentos disponíveis atualmente. Desta forma, a educação deve ser direcionada para que os indivíduos tomem conhecimento deste fato (conhecimento como capital) e possam ter acesso aos meios que lhes possibilitem viver em um mundo em constante mutação.

O desafio cívico constitui-se no quarto ponto nevrálgico da educação contemporânea. $O$ crescente individualismo favorece a diminuição da responsabilidade e solidariedade de forma sistêmica. Para Morin (2001a), um número cada vez maior de indivíduos torna-se mais indiferente à imensa parcela da população que se encontra à margem dos avanços obtidos tanto pelos membros da cultura humanista quanto pelos da científica. A modernidade consolidou essa postura individualista por meio de uma racionalidade simplificadora que gerou o agravamento das questões éticas.

Por outro lado, a população mundial vem perdendo o direito ao conhecimento. Tal afirmativa se constitui em um paradoxo, dado o contexto contemporâneo em que a informação transita e acontece de forma tão rápida. Com a rapidez e a quantidade incomensurável de informações, todavia, a maioria dos cidadãos dispõe de pouco tempo e reduzida habilidade para selecionar e organizar as informações recebidas e convertê-las em conhecimento. Ao mesmo tempo que o acesso e a rapidez no número de informa- 
ções trouxeram uma nova maneira de se comunicar, também criaram abismos sociais, uma vez que nem todos os indivíduos dispõem dos meios para acessá-las, o que acentua a desigualdade social. O próprio Morin afirma que o cidadão contemporâneo "tem direito de adquirir um saber especializado com estudos ad hoc, mas é despojado, enquanto cidadão, de qualquer ponto de vista globalizante ou pertinente" (2001a, p. 19).

O quinto desafio é o "desafio dos desafios", que seria ressaltar a interdependência dos desafios elencados anteriormente. Qualquer "reforma" educacional que busque alterar simplesmente os conteúdos, ou o espaço físico, tenderá ao insucesso por partir da mesma premissa do problema: a fragmentação. O parcelamento de soluções não faz frente a problemas globais, pois não conseguirá perceber o principal desafio que é juntar o que se encontra disjunto, aproximar o distante; isto é, eliminar a hiperfragmentação e a divisão entre a cultura humanista e a cultura científica.

Esta reforma é mais que uma simples mudança de conteúdos ou uma reformulação de disciplinas, é uma "Reforma de Pensamento"; 5 constituindo-se, antes de tudo, em uma reforma paradigmática e não programática. Morin resume tal raciocínio ao afirmar que "a reforma do ensino deve levar à reforma do pensamento, e a reforma do pensamento deve levar à reforma do ensino" (2001a, p. 20).

Em suma, os principais desafios da educação contemporânea, conforme Edgar Morin descreve, são apresentados sinteticamente no Quadro 1::

Quadro 1 - Principais desafios da educação contemporânea

\begin{tabular}{|l|l|}
\hline Desafios 1 & Desafio da dissociação e fragmentação entre os diferentes campos do conhecimento. \\
\hline Desafios 2 & Desafio da cisão entre a cultura humanista e a cultura científica. \\
\hline Desafios 3 & $\begin{array}{l}\text { Desafio do conhecimento como maior e mais importante capital, e sua crescente impor- } \\
\text { tância tanto no plano social como individual. }\end{array}$ \\
\hline Desafios 4 & $\begin{array}{l}\text { Desafio cívico de contrapor ao crescente individualismo, que favorece a diminuição da } \\
\text { responsabilidade e solidariedade de forma sistêmica. }\end{array}$ \\
\hline Desafios 5 & $\begin{array}{l}\text { Desafio dos desafios, que revela a interdependência entre os desafios elencados anterior- } \\
\text { mente, relembrando que ações isoladas pouco ou nada podem fazer diante de desafios } \\
\text { multifacetados. }\end{array}$ \\
\hline
\end{tabular}

Fonte: Os autores.

Como vimos, a fragmentação gera vários desafios que devem ser enfrentados no campo educacional, mas necessitamos lembrar que a divisão é uma ação humana e a aproximação também pode ser.

A visão epistêmica da complexidade apresentada aqui resumidamente constitui-se em base teórica importante para ações interdisciplinares e transdisciplinares, visto que, o "Pensamento Complexo" busca o diálogo entre as visões cartesiana (fragmento - divisão) e a visão holística (todo - conjunto). Vale lembrar que esse diálogo caracteriza a complexidade, ou seja, para compreender realmente algo necessitamos fazer o eterno movimento entre o fragmento e o todo e não optar por um dos extremos.

5 próprio Paulo Freire em um diálogo com Ira Shor alerta que as transformações educacionais ultrapassam as fronteiras das reformas técnicas e estruturais (que são importantes), mas exigem acima de tudo uma "relação diferente com o conhecimento e com a sociedade" (Freire; Shor, 2001, p. 48). 
Acreditamos que a Interdisciplinaridade e a Transdisciplinaridade, fecundadas pela Epistemologia da Complexidade, possam promover esse diálogo na Educação Básica, proporcionando aos educandos uma compreensão mais aprofundada ao vivenciar ações cartesianas (disciplinar - isolada) e ações holísticas (interdisciplinares - conjuntas).

Prosseguiremos demonstrando como a Interdisciplinaridade e a Transdisciplinaridade podem contribuir epistemologicamente e metodologicamente para a construção de ações pedagógicas que possam contrapor-se aos desafios citados.

\section{INTERDISCIPLINARIDADE E TRANSDISCIPLINARIDADE: Princípios Para um Conhecimento Pertinente}

Partimos do pressuposto de que o conhecimento produzido em ações interdisciplinares e transdisciplinares apresenta uma configuração diferente do conhecimento produzido em ações disciplinares. Assim, a Interdisciplinaridade, por ser fruto da interação/esforço de vários educadores (responsáveis por diferentes disciplinas ou ações técnico-pedagógicas), apresenta uma potencialidade de aprofundamento maior que a produção isolada.

Por outro lado a Transdisciplinaridade, ao buscar o reconhecimento e valorização de todos os saberes em uma perspectiva horizontal e não hierarquizada, traz a possibilidade de uma incursão mais profunda nas mais diversas áreas do conhecimento, por meio de trocas teóricas, a partir de uma educação universal e planetária que dialoga com uma visão geral de compreensão da natureza e da vida humana, levando à reflexão dos problemas intrínsecos na sociedade.

Ao adotarmos as duas perspectivas - "Inter e Transdisciplinaridade" - neste estudo como possibilidades fecundas de intervenção no ambiente escolar, compreendemos que, ainda que seus conceitos e concepções também caminhem entre divergências, elas convergem e se aproximam por meio de uma noção de conjunto, de busca por uma globalidade, que contribui para que o sujeito entenda e atue sobre a realidade complexa de nossa vida contemporânea. Dialogamos no sentido de que um objeto, uma investigação, uma ação, uma descoberta, um aprendizado, precisa de ações inter e transdisciplinares que evidenciem as várias possibilidades, olhares e facetas que se fundem para explicar diferentes fenômenos interconectados.

As visões inter e transdisciplinar não são as mesmas, não são únicas, nem tampouco unânimes, mas dentro de uma abordagem ancorada na epistemologia da complexidade, apresentam estruturas que potencializam o processo de ensino/aprendizagem a partir de um olhar mais abrangente de sociedade, educação e conhecimento. Para que elas se efetivem, na prática, fazem-se necessárias ações pedagógicas e metodologias de ensino que garantam sua concretização, que tragam à superfície a pertinência do conhecimento.

A partir desse olhar inter e transdisciplinar, abordaremos o conhecimento na perspectiva de "conhecimento pertinente". Assim, prosseguiremos nossas exposições, fornecendo direcionamentos sobre o que seria "um conhecimento pertinente" e como 
a educação pode percebê-lo e auxiliar sua emersão e consolidação. Dessa maneira, chegaremos à reflexão dos problemas de natureza global que se fazem presentes na sociedade e aos seus desdobramentos.

O conhecimento dos problemas globais tem importância crucial para uma educação bem-sucedida e pertinente, sob pena de uma grave lacuna na formação humana; em outras palavras, a Inter e a Transdisciplinaridade (quando bem planejadas e executadas), efetivamente, promovem uma visão global do fenômeno estudado, para facilitar aos educandos uma compreensão mais crítica e aprofundada.

A educação contemporânea deveria estar preocupada com as injunções cotidianas deste "novo cidadão", cada vez mais envolvido com os contextos planetários, tendo em vista que o crescimento tecnológico e suas facetas propiciaram uma maior rapidez no fluxo de informações e vêm exigindo desses novos sujeitos uma postura mais reflexiva a respeito dos acontecimentos cotidianos e globais. Dessa maneira, a escola como receptora desse "cidadão do mundo" precisa ampliar o seu papel, pois sua função social também envolve a construção de valores éticos, a partir de uma reflexão profunda que não se limita mais aos saberes acadêmico-científicos, mas que se expande para além de seus muros, extravasando sobre o emaranhado imprevisível do cotidiano.

Para que estas ações educativas tenham êxito seria necessário contemplar, segundo Morin, quatro pontos básicos: o contexto, o global, o multidimensional e o complexo. O trato das informações de forma fragmentada pouco ou nada colabora para a compreensão de um determinado processo. Assim, é cada vez mais necessário situar os dados para que possam fazer sentido, ou seja, possibilitar uma "contextualização".

A percepção das ligações que compreendem as diversas partes relacionadas ao contexto configura-se como uma visão geral ou global. Dessa forma, o global possui potencialidades muito maiores que a simples soma dos contextos (relação não linear e não reducionista entre todo e parte expressa por Pascal) (PASCAL, 2003).

Ao buscar conhecer o todo e as partes, a partir da premissa de que o "conhecimento pertinente" é multidimensional, somos conduzidos a uma compreensão complexa do "real". Dessa maneira, o conhecimento escolar contemporâneo deveria encarar a complexidade, isto é, o que está "tecido junto"; interdependente e inter-retroativo entre as partes e o todo, o todo e as partes e as partes entre si, ou seja, a "realidade complexa dos fenômenos", como um princípio articulador que ajuda a dar sentido e significância às abstrações trazidas pela racionalidade do conhecimento científico no contexto da realidade concreta.

Dessa forma, parece-nos adequado detalhar os quatro princípios básicos do conhecimento pertinente, elencados por Morin (2011), como princípios que também abarcam as perspectivas inter e transdisciplinares, com o intuito de possibilitar a transcendência de uma visão simplista e restrita no que tange à produção de conhecimentos na Educação Básica:

- O Contexto: parte da ligação dos temas tratados com a realidade dos seres humanos que os estudam; 
- O Global: busca uma visão abrangente de um determinado tema, travando uma relação realimentadora e não hierárquica entre os elementos constituintes e o todo do fenômeno;

- O Multidimensional: concebe a multirreferencialidade de um determinado tema;

- O Complexo: constata que tanto os seres que discutem quanto o tema discutido são complexos, e que devemos procurar ações ativas na realidade social, pois somos coconstrutores do real, e ações micro (particulares) podem influenciar questões macro (gerais).

O conhecimento pertinente, nessa perspectiva, configura-se como produto e produtor de um pensar complexo que se mostra necessário e urgente nos processos educativos. Dessa forma, seja qual for a área do conhecimento ou o nível de ensino, a grande preocupação dos atores educacionais deve girar em torno de também propiciar ações globalizadoras aos educandos, que mobilizem seus pensamentos, percepções e atitudes para o universo complexo de nossa vida contemporânea. Tais ações podem ser contempladas por meio da Inter e da Transdisciplinaridade pois, dentro da educação escolar, ambas buscam promover rupturas com uma pedagogia tradicional, instrutiva, disjuntiva, passiva e bancária, assumindo o grande desafio de ensinar perseguindo a pertinência do conhecimento, que é fruto da contextualização e da compreensão dos diversos saberes.

A seguir analisaremos sucintamente a base teórica sobre as características da Interdisciplinaridade e da Transdisciplinaridade, com o intuito de fornecer maior fundamentação que possa orientar, sem tentar imprimir receitas ou fórmulas mágicas, o planejamento e execução de ações inter e transdisciplinares.

\section{INTERDISCIPLINARIDADE E TRANSDISCIPLINARIDADE COMO ENFRENTAMENTO AOS DESAFIOS: Apontamentos Para a Sua Compreensão}

Seguiremos aqui discutindo os pressupostos históricos, teóricos e metodológicos da Disciplinaridade, Plurimultidisciplinaridade e da Inter e Transdisciplinaridade, com vistas a um maior esclarecimento dos limites e possibilidades de cada uma dessas propostas.

Ao observamos o cenário da sociedade contemporânea, encontramos na fragmentação do conhecimento humano duas faces distintas de uma mesma moeda, pois, ao mesmo tempo em que, aparentemente, identificam-se avanços fundamentais para a vida moderna, também se experimentam mazelas sociais incomensuráveis. Isso porque, por meio da criação de zonas especializadas em produção e distribuição de bens e serviços, o aparato científico hiperespecializado tem propiciado avanços inegáveis na qualidade de vida da população mundial. Prova disso é o surgimento e aprimoramento de novas tecnologias da informação, de medicamentos, de transportes, entre outros. Juntamente com esses avanços, contudo, deparamo-nos com o risco de criação do "dogma da fragmentação", ou seja, acreditar que esta divisão da vida em campos de conhecimento é "natural", necessária, inevitável e irreversível. 
O processo de fragmentação dos saberes, oriundo de uma racionalização fechada e doutrinada por modelos de pensamento mecanicistas e deterministas, trouxe, como consequência, a simplificação exacerbada do sujeito, do humano, bem como de suas formas de perceber e atuar no mundo (MORIN, 2011). Segundo Sommerman (1999, p. 3), a racionalidade disjuntiva da ciência moderna provocou uma dramática redução do "real". Em suas palavras:

A atenção da pesquisa do homem passou a ser dirigida para um único nível de realidade, o nível sensível, que, evidentemente, foi imensamente enriquecido. Empregando apenas a sua faculdade discursiva, analítica, o homem fragmentou cada vez mais esse nível do real; pensando com isso poder compreender o todo a partir da decomposição das partes.

Foi justamente a partir deste processo de decomposição das partes de um real complexo e global que emergiu a Disciplinaridade. Esta consiste na matriz epistêmica da organização dos saberes humanos divididos em disciplinas. Um sistema composto por um só nível de realidade, com múltiplos objetos e campos de conhecimento (disciplinas), caracterizados pela separação e incomunicabilidade entre si, contando com conceitos, linguagens, teorias e saberes que são específicos de cada área, e permanecem fechados em si mesmos.

De acordo com Torres-Santomé (1998), as disciplinas são formas de organizar e delimitar um determinado campo de trabalho, de concentrar as pesquisas, os conhecimentos e as experiências dentro de um ângulo de visão específico. Por esta razão, cada disciplina nos oferece uma imagem particular da realidade, que se expressa apenas pelo recorte que está situado dentro do ângulo de seus objetivos, impondo-nos uma forma peculiar de pensar, que caminha de acordo com as intencionalidades e limites de cada área.

No campo da educação escolar básica, a organização dos conteúdos e do trabaIho pedagógico se constituiu, historicamente, sob a égide do modelo linear disciplinar, caracterizado pela justaposição de disciplinas, conformadas, na maioria das vezes, de maneira arbitrária e hierárquica. Esta conjuntura compromete a meta fundante da educação de fomentar o conhecimento a partir da compreensão do mundo, estimulando a capacidade do educando de intervir de forma crítica na realidade complexa na qual se insere (TORRES- SANTOMÉ, 1998).

O desejo de reaproximar as disciplinas, todavia, apresenta-se forte e vigoroso, não sendo fato isolado ou recente. A indispensável necessidade de ligações entre as diferentes disciplinas é atestada pelo surgimento da Pluridisciplinaridade, da Multidisciplinaridade, da Interdisciplinaridade e Transdisciplinaridade durante o século 20.

A Pluridisciplinaridade diz respeito ao estudo de um tópico de pesquisa não apenas em uma disciplina, mas em várias ao mesmo tempo. Nicolescu (2005) exemplifica isso por meio de uma análise de uma pintura, como a de Giotto, que poderia ser estudada não apenas dentro da História da Arte, mas também dentro da História das Religiões, da História Europeia e da Geometria. Outro exemplo seria a "Filosofia Marxista", que poderia ser estudada pelo enfoque da Filosofia combinada à Física, à Economia, à Psi- 
canálise ou à Literatura. O objeto estudado seria enriquecido pela associação das perspectivas das várias disciplinas. Além do mais, nossa compreensão do objeto em termos da própria disciplina em questão também seria aprofundada por esta fértil abordagem.

A Multidisciplinaridade, segundo Nicolescu (2005), comporta um conjunto de disciplinas, mas esse conjunto está sempre a serviço da disciplina-foco. Em outras palavras, a abordagem multidisciplinar não ultrapassa as fronteiras disciplinares, enquanto sua meta permanece nos limites do quadro de referência da pesquisa disciplinar. Dessa forma, podemos perceber uma aproximação (até confusão) entre as definições da Pluri e da Multidisciplinaridade.

Conforme Assmann (1998, p. 166), os termos estão tão imbricados que sua conceituação separada torna-se impossível, levando o autor a defini-los conjuntamente como:

Caracterização do enfoque científico e pedagógico aplicado a atividades e projetos que prevêem a participação de especialistas de várias disciplinas, permanecendo praticamente cada qual com a visão mais ou menos restrita de sua área.

Ao contrário da Pluri e da Multidisciplinaridade, que mantêm seus objetivos dentro do mesmo quadro de referência da pesquisa disciplinar, a Interdisciplinaridade traz uma perspectiva de interação entre diferentes áreas disciplinares; avançando no sentido de não procurar o agenciamento de simples aglutinação entre campos do conhecimento, mas, sim, de imprimir o diálogo, a interdependência e o intercâmbio nas relações que estabelece. Assmann (1998, p. 162) traduz esta concepção em seus escritos quando destaca que a Interdisciplinaridade consiste em um

enfoque científico e pedagógico que se caracteriza por buscar algo mais do que mera justaposição das contribuições de diversas disciplinas sobre um mesmo assunto, e se esforça por estabelecer um diálogo enriquecedor entre especialistas de diversas áreas científicas sobre uma determinada temática. Aplica-se a problemas, atividades e projetos que ultrapassam a capacidade de uma só área disciplinar. 0 conceito expressa a consciência dessa limitação das disciplinas específicas, mas não transforma isso necessariamente num questionamento epistemológico mais radical, como o faz a Transdisciplinaridade.

No que tange a sua emergência, de acordo com Fazenda (1994), Georges Gusdorf ${ }^{6}$ foi o primeiro a sistematizar uma proposta de trabalho interdisciplinar ao solicitar à Unesco, em 1961, a constituição de um grupo de especialistas diversos, voltados para pesquisas nas Ciências Humanas. Tal projeto, todavia, não foi aprovado, mas a produção individual do autor marcou o surgimento efetivo da teorização sobre a Interdisciplinaridade.

Em 1970, a Organização para a Cooperação e o Desenvolvimento Econômico (OCDE) promoveu, em Nice, um seminário internacional ${ }^{7}$ sobre a Interdisciplinaridade, do qual surgiu um grupo de trabalho que lançou em 1972 o primeiro documento, o qual apresentou uma sistematização do conceito interdisciplinar.

\footnotetext{
${ }^{6}$ Filósofo francês e professor em Estrasburgo desde 1952.

${ }^{7}$ Este evento conta com a participação de Piaget, fato que marca não só o início da Interdisciplinaridade, mas também da Transdisciplinaridade.
} 
No Brasil, os dois maiores divulgadores dessa área são Ivani Fazenda e Hilton Japiassu, cujas formações acadêmicas são marcadamente francesas. As referências de ambos são muito semelhantes e apresentam Gusdorf como autor de base. A divulgação deste tema iniciou quando Japiassu, em 1976, lançou o livro Interdisciplinaridade e a patologia do saber (fruto da tese de Doutorado defendida em Paris, em 1975) que contou com o prefácio do próprio Gusdorf.

Ivani Fazenda, por sua vez, conheceu a Interdisciplinaridade por meio de Japiassu, e juntos constituíram um dos mais eficazes programas de pesquisa sobre o tema nos meios educativos brasileiros. Tal programa vem investigando, ao longo das últimas décadas, diversos aspectos relevantes ao tema, com uma dezena de obras publicadas, inaugurando um contundente movimento interdisciplinar no país.

O tema também é muito trabalhado pelo pesquisador francês Pierre Weil (Universidade Holística). Este autor concebe a Interdisciplinaridade e a Transdisciplinaridade como exigências dos diversos métodos empregados para a construção da visão holística de mundo.

No que se refere às suas configurações, para Nicolescu (2005), a Interdisciplinaridade pode ser distinguida a partir de três graus:

a) O grau de aplicação: quando, por exemplo, são transferidos métodos da Física Nuclear para a Medicina, resultando na criação (e subsequente aplicação) de novos tratamentos contra o câncer;

b) O grau epistemológico: quando há transferência de "matrizes de pensamento", como quando se transferem elementos da lógica formal para a área do Direito geral, gerando um novo campo de análise na epistemologia do Direito;

c) O grau de geração de novas disciplinas (ou áreas de conhecimento): exemplos clássicos ocorreram quando métodos da Matemática foram transferidos para a Física; geraram a Física-matemática; quando foram transferidos métodos da Física de partículas para a Astrofísica, produziu-se a Cosmologia quântica, ou quando foram transferidos métodos computacionais para a arte, obteve-se a arte digital.

No campo específico da educação a Interdisciplinaridade, ao longo de sua trajetória histórica, seja como princípio de produção do conhecimento ou como prática docente, vem recebendo diversos contornos e sendo abrigada em diferentes discursos que transitam, desde perspectivas consideradas mais funcionalistas ou tecnocráticas, passando pelos construtos das teorizações estruturalistas, até concepções pós-estruturalistas. Ainda que nossa intenção não seja o aprofundamento de cada um dos diferentes olhares lançados para a Interdisciplinaridade, consideramos fundamental sinalizar para a natureza polissêmica e imprecisa do termo e para sua não unanimidade, que a insere em um campo conflituoso e diversos (OZELAME; OZELAME, 2015; MORIN, 2001a).

Neste mesmo viés, a Transdisciplinaridade apresenta-se na literatura imersa em múltiplas perspectivas que a aproximam, distanciam-na e, por vezes, integram-na à noção de Interdisciplinaridade. No bojo dessas diferentes concepções, a Transdisciplinaridade aparece, ora como uma etapa superior à Interdisciplinaridade, por buscar a superação do plano de interação entre as diferentes disciplinas, transgredindo as fronteiras teóricas tradicionais e chegando a um estágio de unificação epistemológica; ora 
se apresenta em diferentes tipos e graus, que denotam um processo de constante diálogo entre os prefixos "inter" e "trans" (TORRES-SANTOMÉ, 1998; JAPIASSU, 2006; SOMMERMAN, 2006).

Embora boa parte da literatura que aborda a questão transdisciplinar indique seu surgimento a partir de um movimento contestatório da ciência moderna, baseada em uma linha cartesiana fragmentária, Morin (2005) admite que o próprio desenvolvimento desta ciência moderna, como a conhecemos, é fruto de um meneio transdisciplinar. Para o autor, "a ciência nunca teria sido ciência se não tivesse sido transdisciplinar" (MORIN, 2005, p. 135). O autor destaca, ainda, que a confluência de métodos, o emprego de postulados implícitos a todas as disciplinas, - como a objetividade, a linguagem matemática e a formalização - são exemplos de elementos que traduzem uma unidade epistêmica própria da Transdisciplinaridade. Esta unidade, no entanto, repousa em um paradigma cartesiano, marcado pelo empirismo, positivismo, pragmatismo e por imperialismos teóricos.

Diante desse contexto, Morin sinaliza que a verdadeira questão não implica se "fazer transdisciplinar", mas, sim, em "que transdisciplinar é preciso fazer?". Nesse sentido, o autor propõe uma "nova" Transdisciplinaridade, alicerçada pelo "paradigma de complexidade, que, ao mesmo tempo, separe e associe, que conceba os níveis de emergência da realidade sem os reduzir às unidades elementares e às leis gerais" (2005, p. 138).

Para Petraglia (2013), o esforço pela instauração de um paradigma transdisciplinar complexo encaminha vários olhares na mesma direção, que se contrapõem e se complementam na mesma medida. É desse pluralismo de ideias, portanto, que a própria Transdisciplinaridade se nutre e da religação dos diversos tipos de pensamento, imersos em consensos e dissensos que o pensamento complexo se constitui.

Diante disso, conforme argumenta Sommerman (2006), a Transdisciplinaridade assume uma natureza difusa e não binária baseada em três pilares epistêmico-pedagógicos:

1. A complexidade: que emerge da pluralidade e multirreferencialidade dos dados encontrados pelos avanços das Ciências Naturais e por alguns campos das Ciências Humanas, especialmente da Antropologia. A complexidade é uma visão mais ampla que rompe com a perspectiva do reducionismo, do holismo, que negligencia as partes para compreender o todo. Para além disso, essa visão requer uma nova postura que sai da linearidade e prioriza o movimento circular, em que se transita da parte para o todo e vice-versa, buscando a compreensão do fenômeno.

2. A lógica do terceiro incluído: emerge das Ciências, em particular da Física, e trata-se da formulação de uma nova lógica, antagônica e complementar ao terceiro axioma identitário de Aristóteles, que é o "Princípio do terceiro excluído".

3. Os diferentes níveis da realidade: emergem das ciências contemporâneas (História, Filosofia e Antropologia), como também das tradições da História da humanidade. Entre os diferentes níveis de realidade devem surgir "zonas de re- 
sistência" que constituem o espaço privilegiado do fenômeno transdisciplinar. Significa dizer que, em todas as várias dimensões da realidade de um objeto, existe certa quantidade de matéria comum a todas as dimensões.

Na concepção de Nicolescu (2005), por mais que a Transdisciplinaridade apresente uma dinâmica particular, um caráter radicalmente distinto em relação à Disciplinaridade, no que tange a seus pressupostos transgressores das barreiras que delimitam campos de ação e de conhecimento, há de se manter alerta para não cair no equívoco de absolutizar suas distinções, correndo o risco esvaziá-la, recaindo no reducionismo - foco de suas denúncias e críticas. Assim, o autor advoga que tanto a Disciplinaridade quanto a Multidisciplinaridade, a Pluridisciplinaridade, a Interdisciplinaridade e a Transdisciplinaridade são cinco flechas lançadas de um único arco, o conhecimento.

Como vimos, as várias formas de organização do conhecimento humano (quer na Academia, quer na Educação Básica) correspondem às visões epistêmicas que compreendem e validam separações ou aproximações com ações importantes na compreensão dos fenômenos. Assim sendo, para facilitar o entendimento dessas distintas formas de compreensão e organização realizaremos a seguir uma síntese conceitual/ estrutural didática com o auxílio de representações gráficas. Nestas representações usamos figuras geométricas, nas quais: os cubos representam os campos disciplinares ou as disciplinas; os círculos compõem o campo conceitual/disciplinares; as setas simulam os movimentos de compreensão da disciplina ao objeto e o cilindro corresponde ao objeto de conhecimento investigado pela disciplina.

Dessa maneira, temos a Figura 1 que mostra da Disciplinaridade, entendendo-a como um sistema composto por um só nível de realidade, múltiplos objetos e múltiplos campos de conhecimentos (disciplinas), caracterizando-se por não apresentar interação e nem troca teórica, mas, sim, uma separação e incomunicabilidade com campos disciplinares fechados.

Figura 1 - Disciplinaridade

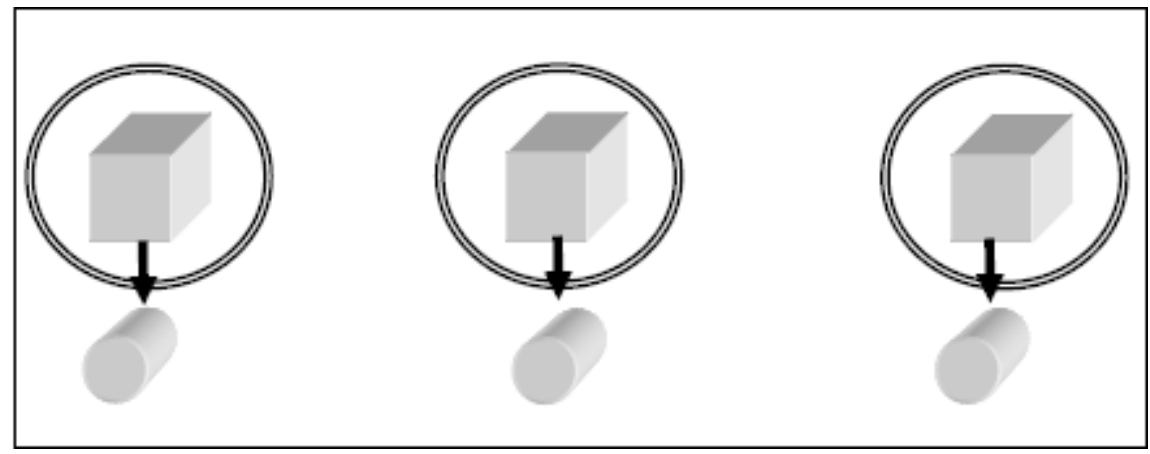

Fonte: SANTOS, 2012, p. 60.

Temos na Figura 2 a representação da Pluridisciplinaridade ou Multidisciplinaridade, caracterizadas por um sistema composto por um só nível de realidade, um só objeto e campos de conhecimentos múltiplos, primando por cooperação e comunicação reduzida. Estão intimamente relacionadas à justaposição, na qual se reconhece a necessidade de aproximação. 
Figura 2 - Pluridisciplinaridade ou Multidisciplinaridade

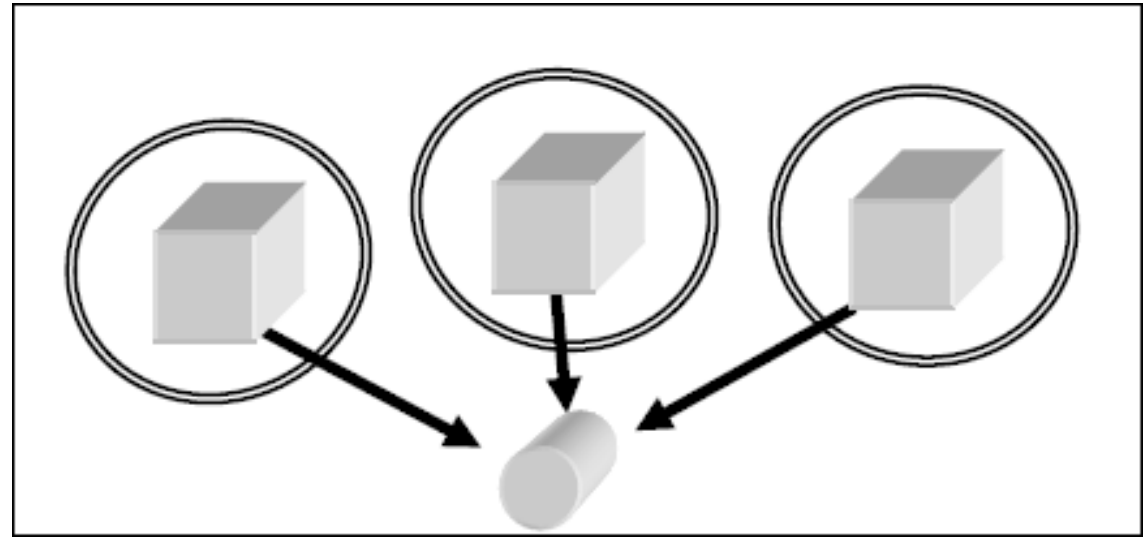

Fonte: SANTOS, 2012, p. 60.

Na Figura 3 apresentamos a Interdisciplinaridade, compreendida como um sistema formado por um só nível de realidade, um só objeto e campos de conhecimento múltiplos, e caracterizado por cooperação, coordenação e troca teórica. Os campos disciplinares, contudo, permanecem afastados, mas de maneira permeável. Podemos constatar pela representação gráfíca que a Figura 3 apresenta significativas mudanças, colocando a Interdisciplinaridade como um meio possível para que aconteça efetivamente uma troca e interação entre as áreas do conhecimento, não obstante a presença disciplinar ainda esteja presente.

Figura 3 - Interdisciplinaridade

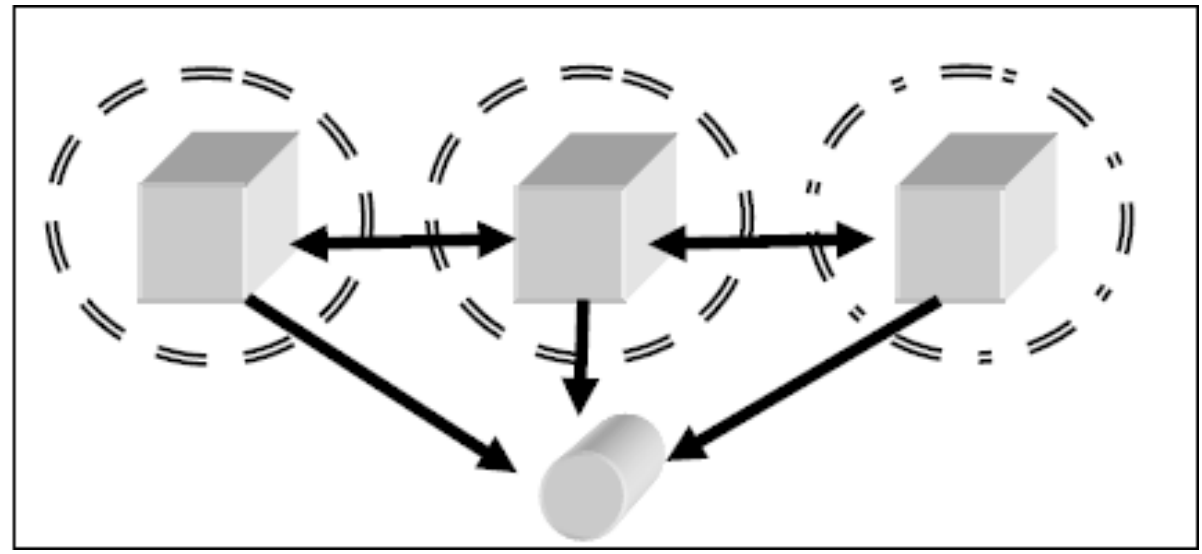

Fonte: SANTOS, 2012, p. 61.

A Figura 4 evidencia a Transdisciplinaridade como um sistema composto por múltiplos níveis de realidade, campos de conhecimento também múltiplos e um objeto. Caracterizado por intensa cooperação, coordenação e comunicação (troca epistêmica), nos quais os campos disciplinares são muito permeáveis e se interpenetram, somando as várias possibilidades de compreensão possíveis para juntas construírem a representação mais completa e multifacetada do objeto. 
Figura 4 - Transdisciplinaridade

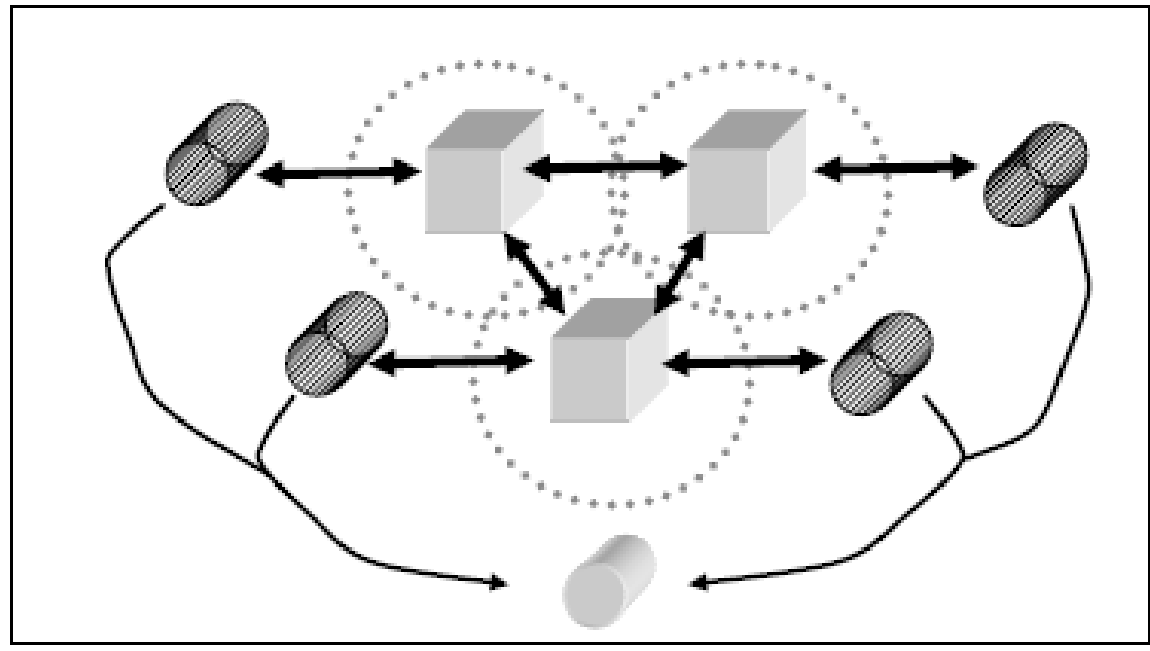

Fonte: SANTOS, 2012, p. 62.

Assim, observamos que cada visão epistêmica apresenta um sistema composto por diferentes facetas que se relacionam por meio de variadas expressões do conhecimento. Numa tentativa de demonstrarmos de maneira mais clara e dinâmica as diferentes perspectivas disciplinares, compreendemos a importância de ampliarmos e aprofundarmos as possibilidades dessa discussão.

Por fim, prosseguiremos esse estudo discutindo algumas implicações da Interdisciplinaridade e da Transdisciplinaridade no campo da Educação, salientando como os educadores podem colaborar valiosamente para a construção de um conhecimento pertinente.

Ao nos ancorarmos sob as fundamentações do paradigma da Complexidade, procurando imprimir os traços de um conhecimento pertinente no âmbito da Educação Básica, buscamos atuar no campo das aproximações entre os princípios da Inter e da Transdisciplinaridade, sem desconsiderar suas particularidades e dissonâncias. Esta escolha se dá, em primeira instância, por estarmos de acordo com os escritos de Nicolescu (2005), que nos alerta para o risco de tornar a Transdisciplinaridade tão absoluta a ponto de sua abordagem perpetuar aquilo que é alvo de suas críticas: o imperialismo teórico. Em segunda instância, porque acreditamos que o trabalho desenvolvido no cotidiano escolar abriga características que exigem maior flexibilização para que os processos educativos possam acontecer em diferentes tempos e espaços de aprendizagem, valorizando o imprevisível e a incerteza, que também são partes da produção do conhecimento.

Nesse sentido, defendemos que, ao perseguirmos o desenvolvimento de projetos interdisciplinares, abrimos margem para a possibilidade de vivenciarmos cada vez mais experiências transdisciplinares. Por conseguinte, ao desbravarmos este caminho, também expandimos a oportunidade de encontrar pequenas fissuras no próprio cotidiano imprevisível e incerto da realidade complexa, que nos permitam incidir de forma mais profunda e contundente sobre as barreiras, os arranjos que nos isolam uns dos outros, de nós mesmos e do mundo a nossa volta. 
Com base nessa perspectiva, salientamos que ações interdisciplinares e transdisciplinares podem ser propostas e organizadas por qualquer ator do ambiente escolar. Sendo assim, os docentes, uma vez detentores dos saberes metodológicos e epistemológicos específicos da Inter e da Transdisciplinaridade podem construir, conjuntamente com os educandos e o corpo técnico-administrativo das instituições, o planejamento, a execução e a avaliação de ações dessa natureza.

Tal postura (aproximação dos saberes) é amplamente incentivada em documentos oficiais brasileiros desde os Parâmetros Curriculares Nacionais (1997), que preveem a articulação das disciplinas e a transversalidade dos saberes, até as atuais propostas da Base Nacional Comum Curricular (2015), que apontam para a necessidade de articulações interdisciplinares e transversais consistentes.

Acreditamos, todavia, que o pouco envolvimento docente em ações inter e transdisciplinares é derivado de vários fatores, entre eles: a estrutura organizacional das escolas e a insegurança dos docentes, decorrente, em grande medida, das formações fragmentadas, em que a Inter e a Transdisciplinaridade são faladas, mas pouco exercitadas. O que significa que, embora os estudos referentes a essas questões estejam acontecendo desde o início da década de 70 no Brasil, ainda é possível observar que pouco se tem saído do campo da reflexão para ações efetivas na prática.

A fim de lançarmos mão de atitudes mais significativas, a seguir buscaremos fornecer direcionamentos metodológicos sobre a construção de projetos pedagógicos inter e transdisciplinares com vistas a auxiliar os docentes da Educação Básica.

\section{METODOLOGIA DE PROJETOS:}

\section{Introdução de Projetos Inter e Transdisciplinares na Educação Básica}

Em nossa experiência e nas tentativas de concretização de ações inter e transdisciplinares, chegamos a algumas conclusões no que respeita à possibilidade de sua adoção na Educação Básica. A primeira delas gira em torno da estrutura organizacional, que além de ser fragmentada, é fragmentária, gerando divisões em outros setores que acabam criando barreiras para a efetivação de ações dessa natureza. No sentido de buscar uma alternativa para diminuir tais barreiras, necessitamos do apoio do corpo técnico-administrativo, a fim de assegurar espaços institucionais de planejamento capazes de transpor as dificuldades, possibilitando a concretude dessas ações.

Somando-se a isso, a busca da aproximação dos saberes deve fazer parte do Projeto Político-Pedagógico e dos planejamentos, garantindo assim apoio institucional (alocação de carga horária para planejamento/realização, apoio material), pois se trata de um processo que requer além de apoio, reconhecimento do seu grau de importância para a escola; e, dito isso, as responsabilidades devem ser divididas, sobretudo por serem ações que tradicionalmente remetem apenas à figura do professor maior empenho e compromisso, inclusive quando estes utilizam suas horas de folga e seus próprios recursos financeiros para fazer com que as ações aconteçam efetivamente. 
Outro ponto importante é a forma de se introduzir a Inter e a Transdisciplinaridade na escola. Acreditamos que um meio eficiente para isso seja por intermédio da "Metodologia de Projetos" (SANTOS, 2006), na qual os atores selecionam um objeto de estudo e constroem um projeto de intervenção que será desenvolvido com os educandos com o auxílio dos docentes.

Destacamos que o trabalho com projetos deve buscar envolver o educando da maneira mais efetiva possível, entendendo que a aprendizagem acontece no processo de produção, nas dúvidas que surgem e nas relações que se criam e subsidiam novos olhares, descobertas e a construção do conhecimento. Para Hernández (1998), o trabalho por projetos "não deve ser visto como uma opção puramente metodológica, mas como uma maneira de repensar a função da escola". Isso requer não apenas uma mudança de postura didático-metodológica, que se restringe à execução dos projetos, mas o estabelecimento de uma relação indissociável entre teoria e método (SANTOS, 2006).

Uma das vantagens da efetivação de ações inter e transdisciplinares estruturadas na forma de Metodologia de Projetos é a liberdade conferida à instituição. Cada realidade educacional é única e a elaboração dos projetos deve contemplar essas singularidades. Se o projeto vai ser desenvolvido por poucas ou muitas pessoas, se vai durar um longo período ou vai ser mais pontual, cabe a cada grupo definir. Sabendo-se que cada ação presencialmente deve servir de base para uma subsequente, a Inter e a Transdisciplinaridade vão paulatinamente ganhando força dentro do ambiente educativo.

Também não podemos esquecer que o trabalho inter e transdisciplinar prevê uma atuação em conjunto, o que se configura como um dos grandes desafios para o trabalho docente, entretanto é partindo do integrar, do trocar, do transitar, do permear, do fundir pelas diversas áreas do conhecimento que são alcançadas ações efetivamente inter e transdisciplinares. Uma ideia errônea muito difundida é a de que um docente isolado pode fazer essas ações acontecerem a partir de um esforço individual. Acreditamos, no entanto, ser preciso uma troca teórica entre os pares e os demais entes do ambiente escolar, uma vez que nenhum docente pode reproduzir em um monólogo o prolífico diálogo entre os diferentes, pois nenhum autor que teorize sobre a Inter e a Transdisciplinaridade prevê o isolamento e, sim, a aproximação de saberes e sujeitos.

Nesta perspectiva, ressaltamos a importância de se trabalhar de acordo com a ideia de integração e diálogo envolvendo a coautoria dos diferentes profissionais que constituem a escola, bem como enfatizando o protagonismo dos educandos em todo o processo de constituição do projeto. Não devemos nos prender, todavia, à expectativa de alcançarmos a maioria. A ideia de contagiar um grupo maior de atores seria o desejável, mas necessitamos lidar com as dificuldades impostas pelos diferentes contextos. Dessa maneira, ainda que se tenha um grupo reduzido, espera-se que esses atores se unam em busca de produzir novos conhecimentos e se embrenhem na descoberta de novas fontes de mobilização da aprendizagem, pois para trabalhar com projetos é preciso "ter coragem para romper com as limitações do cotidiano, muitas vezes auto-impostas" (ALMEIDA; FONSECA JÚNIOR, 2000).

Por fim, propomo-nos a sistematizar algumas reflexões que possam auxiliar os educadores no planejamento/execução de ações inter e transdisciplinares.

Assim sendo, nós, educadores, devemos ter claro que: 
1. Um projeto existe para auxiliar na predição, organização, coordenação, execução e avaliação de uma ação, seja investigativa ou pedagógica.

2. Um projeto de intervenção inter e transdisciplinar não deve ser intricado no planejamento e muito menos na execução, quer dizer, ele pode ser amplo, mas não complicado.

3. Lembrar que um projeto de intervenção pedagógico inter e transdisciplinar deve manter as características dessa proposta pedagógica, isto é, comunicação, cooperação e coordenação.

4. Um projeto inter e transdisciplinar deve ser planejado de acordo com a disponibilidade dos participantes e suas condições concretas, ou seja, é melhor fazer uma ação curta e bem executada (começo, meio e fim), do que almejar muito e não conseguir realizar tudo, gerando frustração e desânimo. Se o grupo é pequeno ou tem pouca experiência, é melhor começar pequeno e ir ganhando visibilidade e força na escola paulatinamente.

5. Ações inter e transdisciplinares exigem comprometimento dos participantes e colaboração dos gestores. Em outras palavras, durante todo o processo (planejamento, execução e avaliação) devem ser garantidas as condições de execução (carga horária para planejamento e recursos, por exemplo), que podem ser bem utilizadas pelos membros do grupo (docentes, técnicos, educandos, entre outros) e não desperdiçadas.

Prosseguiremos indicando um roteiro que pode ser contemplado no processo de planejamento de um Projeto de Intervenção inter e transdisciplinar.

Antes da escrita do projeto:

1. Levantamento de dados relevantes (escolher o tema que vai ser trabalhado): ouvir a comunidade - docentes, discentes, pais, técnicos e comunidade externa (pode ser feita de forma escrita, em reuniões, ou por qualquer meio que garanta a participação).

Na escrita do Projeto de Intervenção inter e transdisciplinar:

1. Expressar com clareza o tema a ser trabalhado por meio de um título que consiga demonstrar ao restante da comunidade escolar o que se pretende trabaIhar.

2. Escrever uma curta justificativa: um texto resumido que contextualize a necessidade de esse tema ser trabalhado; ou seja, como o tema foi selecionado, que influências ele vem trazendo para a escola e a necessidade de ações pedagógicas nessa direção.

3. Com clareza, definir objetivos: lembre-se que uma ação dessa natureza possui dois tipos de objetivos: um específico (tarefa conceitual, procedimental ou atitudinal de cada disciplina) e um objetivo geral (conceito, procedimento ou atitude que vai ser trabalhada por todos os docentes de todas as disciplinas envolvidas).

4. Definir o período de execução: lembre-se das condições efetivas da escola para que o projeto consiga ser concluído. 
5. Listar os procedimentos metodológicos: estratégias; metodologias; dinâmicas que serão utilizadas pelo grupo ao longo de todo o projeto.

6. Lista de recursos: recursos e/ou infraestrutura física; material e de pessoal que serão utilizadas pelos envolvidos.

7. Fazer um cronograma ${ }^{8}$ com as ações coletivas que deverão ser desenvolvidas juntamente com a divisão dos recursos e das tarefas entre os participantes para que não haja sobrecarga.

8. Definir instrumentos de avaliação: a avaliação poder ocorrer processualmente ou ser realizada ao final do projeto (pode ocorrer juntamente com a culminância). O importante é não abrir mão da avaliação, pois sem ela os esforços do projeto se perdem no ativismo e todo o aprendizado do grupo pode não fomentar outras ações.

\section{CONSIDERAÇÕES FINAIS}

Num esforço de mostrarmos a aproximação, ou mesmo a complementaridade da Inter e da Transdisciplinaridade ao longo desse estudo e a efetivação de suas ações por meio da Metodologia de Projetos, esclarecemos que tanto o conhecimento produzido de maneira disciplinar, que permite ao aluno reconhecer as particularidades de uma determinada disciplina ou campo teórico, quanto o conhecimento inter e transdisciplinar, que levam o sujeito a estabelecer pontes significativas entre os diversos saberes, são de extrema importância para se entender o processo de ensino/aprendizagem e mostrar como este pode acontecer de diferentes maneiras.

Como já referido, a Inter e a Transdisciplinaridade podem ser enriquecidas com a fundamentação da "Teoria da Complexidade", visto que tal visão epistêmica prima por uma análise criteriosa do princípio de fragmentação dos saberes humanos, alertando para o fato de que uma visão fragmentada da realidade pode trazer ganhos inegáveis, mas carecemos em igual medida da reaproximação.

Desse modo, o "conhecimento pertinente" produzido em ações inter e transdisciplinares contribuirá efetivamente com uma educação que consiga auxiliar na formação de cidadãos cada vez mais municiados a lidar com as demandas contemporâneas (ambientais, éticas, entre outras).

Procuramos destacar, também, que a Inter e a Transdisciplinaridade são responsabilidades de todos os atores educacionais. Por fim, apresentamos a "Metodologia de Projetos" como possibilidade válida de efetivação da Interdisciplinaridade e da Transdisciplinaridade em ambientes educativos, tendo em vista as dificuldades estruturais do sistema regular de ensino (estrutura fragmentada e fragmentária), ressaltando alguns reflexos que possam auxiliar os educadores no planejamento/prática/avaliação de ações interdisciplinares cada vez mais cotidianas e fundamentadas.

\footnotetext{
${ }^{8}$ Este cronograma pode ser aprofundado com os objetivos específicos por área, mas isso vai depender do desejo do grupo. Outro ponto importante é que o cronograma deve conter uma forma de encerramento (culminância da ação), envolvendo preferencialmente todos os docentes.
} 


\section{REFERÊNCIAS}

ALMEIDA, F. J.; FONSECA JÚNIOR, F. M. Projetos e ambientes inovadores. Brasília: Secretaria de Educação a Distância - Seed; Proinfo - Ministério da Educação, 2000.

ASSMANN, Hugo. Reencantar a educação: rumo à sociedade aprendente. Petrópolis, RJ: Vozes, 1998.

BRASIL. Secretaria de Educação Fundamental. Parâmetros Curriculares Nacionais: introdução aos Parâmetros Curriculares Nacionais. Brasília: MEC; Secretaria de Educação Fundamental (SEF), 1997. Disponível em: <http://portal.mec.gov.br/seb/arquivos/pdf/livro01.pdf>. Acesso em: 30 set. 2015.

Ministério da Educação. Base nacional comum curricular. Disponível em: <http://basenacionalcomum.mec.gov.br/> Acesso em: 30 set. 2015.

CAPRA, Fritjof. A teia da vida. São Paulo: Ed. Cultrix, 1996.

FREIRE, Paulo; SHOR, Ira. Medo e ousadia: o cotidiano do professor. Rio de Janeiro: Paz e Terra, 2001.

FAZENDA, Ivani. Interdisciplinaridade: história, teoria e pesquisa. Campinas, SP: Papirus, 1994.

HERNÁNDEZ, F. Transgressão e mudança na educação: os projetos de trabalho. Porto Alegre: ArtMed, 1998.

JAPIASSU, Hilton. O sonho transdisciplinar. Rio de Janeiro: Imago, 2016.

MORIN, Edgar; LE MOIGNE, Jean-Louis. A inteligência da complexidade. São Paulo: Fundação Peirópolis, 2000.

MORIN, Edgar; CIURANA, Emilio, MOTTA, Raúl. Educação na era planetária: o pensamento complexo como método de aprendizagem pelo erro e incerteza humana. São Paulo: Cortez; Unesco, 2003.

MORIN, Edgar. Saberes globais e saberes locais: o olhar transdisciplinar. Rio de Janeiro: Garamond, 2000 a. Terra pátria. Porto Alegre: Ed. Sulina, 2000b.

$2001 a$

A cabeça bem-feita - pensar a reforma, reformar o pensamento. Rio de Janeiro: Bertrand Brasil,

. As duas globalizações: complexidade e comunicação uma pedagogia do presente. In: SILVA, Juremir Machado da (Org.). As duas globalizações; complexidade e comunicação uma pedagogia do presente. Porto Alegre: Edipucrs; Ed. Sulina, 2001b.

Ciência com consciência. Rio de Janeiro: Bertrand Brasil, 2002.

Ciência com consciência. Rio de Janeiro: Bertrand Brasil, 2005.

Introdução ao pensamento complexo. Portugal: Instituto Piaget, 2008.

Os sete saberes necessários à educação do futuro. São Paulo: Cortez Editora, 2011.

NICOLESCU, Basarab. O manifesto da transdisciplinaridade. São Paulo: Triom, 2005.

OZELAME, Diego Machado; OZELAME, Josiele Kaminski Corso. Interdisciplinaridade, educação e ensino: um possível deslocamento a partir de impasses e perspectivas. Revista Científica Internacional InterSciencePlace, n. 4, vol. 10, artigo n. 10, out./dez. 2015.

PASCAL, Blaise. Pensamentos. São Paulo: Martins Claret, 2003.

PETRAGLIA, Izabel. Pensamento complexo e educação. São Paulo: Ed. Livraria da Física. 2013. (Coleção contextos da ciência).

SANTOS, Akiko. Pedagogia ou método de projetos? Referências transdisciplinares. CONGRESSO MUNDIAL DE TRANSDISCIPLINARIDADE, 2., 2006. Vitória-ES, Brasil, set. 2006.

SANTOS, Marcio Raiol dos. Transdisciplinaridade e educação: fundamentos de complexidade da docência/discência. Belém: Ed. Açaí, 2012.

SOMMERMAN, Américo. Pedagogia da alternância e transdisciplinaridade. 1999. Disponível em: <www. cetrans.futuro.usp.br>. Acesso em: 30 out. 2015.

Epistemologia. imaginário@mídia.educação.br. Disponível em: <www.cetrans.futuro.usp.br>. Acesso em: 30 out. 2015.

Inter ou transdisciplinaridade: da fragmentação disciplinar ao novo diálogo entre os saberes. São Paulo: Paulus, 2006.

TORRES-SANTOMÉ, Jurjo. Globalização e interdisciplinaridade: o currículo integrado. Porto Alegre: Ed. Artes Médicas Sul, 1998. 